\title{
Quem pensa no bem estar docente? Cartas de tempos pandêmicos
}

\author{
Who thinks about teaching well-being? \\ Letters from pandemic times
}
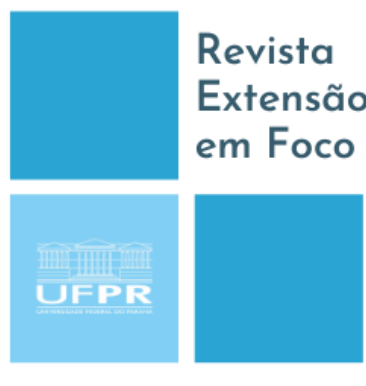

ISSN 2358.7180

\author{
Aline Machado Dorneles ${ }^{1}$
}

\section{RESUMO}

\begin{abstract}
Apresentam-se as cartas da docência como registros vividos em tempos pandêmicos. As cartas remetem reflexões a respeito da escola, da docência e do contexto social e político da educação pública, a partir da escrita narrativa das experiências da própria autora do texto. As cartas também convidam a pensar em quem cuida dos professores e professoras no contexto educativo, e assim fomentar a importância do bem estar profissional. São cartas escritas durante o processo de formação no projeto Cirandar: rodas de investigação na escola, com aposta na escrita narrativa como modo documentar e promover a autoria dos professores participantes. Desse modo, primeiramente as cartas são trazidas como de registro do viver e ser docente em tempos outros, tempos pandêmicos que deslocam o fazer e pensar educativo. Posteriormente, reflexões teóricas são tecidas como possibilidade de fomentar a narrativa como modo de compreender a docência a partir da experiência.
\end{abstract}

Palavras-chave: Experiência. Investigação narrativa. Formação docente.

\section{ABSTRACT}

Teaching letters are presented as records lived in pandemic times. The letters refer to reflections about the school, teaching and the social and political context of public education, based on the narrative writing of the experiences of the author of the text itself. The letters also invite you to think about who cares for teachers in the educational context, and thus foster the importance of professional well-being. These are letters written during the training process in the project Cirandar: research circles at school, with an emphasis on narrative writing as a way to document and promote the authorship of the participating teachers. In this way, first the letters are brought as a record of living and being a teacher in other times, pandemic times that displace educational doing and thinking. Subsequently, theoretical reflections are woven as a possibility to foster the narrative as a way of understanding teaching from experience.

Keywords: Experience. Narrative investigation. Teacher training.

\footnotetext{
${ }^{1}$ Doutora em Educação em Ciências pela FURG. Professora Adjunta da Universidade Federal do Rio Grande - FURG do Programa de Pós-Graduação em Educação em Ciências da FURG, Rio Grande, RS, Brasil. E-mail: lidorneles26@gmail.com. Orcid: https://orcid.org/0000-0001-7110-9378
} 


\section{APRESENTAÇÃO}

Escrever é modo de deixar que nossos silêncios também falem....

Marisa Vorraber Costa (2019)

As cartas que apresento no presente texto é um convite para encontrar na e pela escrita narrativa modos de viver à docência em tempos outros, em que os silêncios das nossas vozes estão pressas nas paredes de nossas casas. Nos afastamos da alegria de estar em sala de aula, de caminhar nos corredores de uma Escola, do reencontro e trocas de sorrisos de viver o cotidiano escolar. Vivemos tempos cruéis e doloridos causados pela pandemia da Covid-19. E, atrelado a isso nós docentes somos também cruelmente atacados pelos governos e pela sociedade que não reconhecem o papel social e humano da escola, que não preservam a vida quando decidem ao retorno de um ensino presencial. A luta mesmo que silenciosa, continua presente, e almejamos vacina para todos e todas, e assim o retorno com vida para as escolas, para os reencontros, sorrisos e abraços.

É preciso deixar que os silêncios também falem, como nos convida Marisa Costa (2019). A autora diz da necessidade de correr os riscos de inventar outras maneiras de não apenas olhar o presente, mas de tentar penetrá-lo cautelosamente, e assim dialogar com as singularidades, que até hoje são inviabilizadas (COSTA, 2019). Ao escrever as cartas, apresentadas a seguir, encontro-me no presente, nos desafios emergidos diante da pandemia, de viver o imprevisível, o inesperado, e como professora buscar na e pela narrativa modos de reinventar o meu fazer e estar na profissão.

Os dias e meses do ano de 2020 me deslocaram, e já se passou um ano, e por vezes questiono-me se iremos conseguir retornar, quando e como iremos retornar. Como resgatar nossos estudantes, quando sua estrutura familiar não tem suporte tecnológico para se fazer presente nas plataformas virtuais de ensino, e nisso penso que os invisíveis ficam ainda mais esquecidos. E, nós professores que buscamos administrar nossos tempos profissionais e de vida dentro das nossas próprias casas, e mesmo diante dos desafios ainda buscamos estratégias para nos fazer presente, e assim tentar resgatar o papel da escola presente e viva na vida de cada um. Mas, quem cuida de nós professores e professoras? É preciso falar do bem estar docente. Por isso, decido partilhar na escrita de cada carta os desejos, os dilemas e as sensibilidades silenciadas. As cartas trazidas são mediadas por perguntas e reflexões que me movem a pensar no bem estar na docência. 


\section{CARTA I - COMO CHEGUEI ATÉ AQUI?}

Rio Grande 24 de setembro de 2020

Viver é um rasgar-se e remendar-se

Guimarães Rosa (1986)

Nos últimos meses, ou melhor, nos últimos 180 dias vividos dentro de casa, de março até o momento da escrita dessa carta posso afirmar que os dias são outros, o viver é outro, o pensar é outro... Rasgar-se e remendar-se nunca foi tão necessário, talvez seja por aí que costuro e remendo meus dias, e assim desejo nas palavras trazidas nessa carta um apresentar-se de mim, mas não como algo pronto e acabado. Pois, como nos diz Guimarães Rosa no livro Grande Sertão: Veredas - [...] o mais importante e bonito, do mundo, é isto: que as pessoas não estão sempre iguais, ainda não foram terminadas - mas que elas vão sempre mudando. Afinam ou desafinam. Verdade maior. É o que a vida me ensinou[...]. No desafinar dos dias, com a insegurança frente ao invisível e cruel vírus que busco me transformar, e quiçá desejo cultivar a esperança frente a crueldade de um vírus e o descompromisso político e ético com a vida das pessoas.

Como professora alimento meu compromisso com as pessoas, e assim almejo criar caminhos que favoreçam a transformação do Outro, afinal não somos sempre iguais, ainda não fomos terminados. Assim, chego no Cirandar 2020 com o desejo de partilhar desafios, angústias e dilemas vividos ao ser professora dentro de casa, frente a tela do computador com as infinitas mensagens que chegam ao todo momento. Desde 2012, na primeira edição do Cirandar, permito-me escrever sobre minha prática educativa, e assim a cada ano encontro no Cirandar uma possibilidade de reencontro com minhas experiências e ao investigar meu próprio fazer profissional também aprofundo o desejo de estudar e, principalmente, na partilha com o Outro ressignifico meus desejos, dilemas e contextos vividos.

Encontro na escrita narrativa uma maneira de expressar meus sentimentos e aprendizagens. O caminho da aprendizagem é longo, pois escrever com sentimento é algo que incomoda, e me desafia o tempo todo. Como professora de Química fui levada na formação inicial a repetições de ideias, teorias, sem ao menos me questionar sobre minha experiência. Mas, esse caminhar me oportunizou a fazer escolhas, e essas escolhas se tornaram inesquecíveis e fazem parte da minha história. Assim, decido na formação 
continuada, em fazer mestrado e doutorado como maneira de encontrar-me, e assim construir caminhos investigativo com o olhar atento ao estudo da experiência.

No Cirandar também encontro modos de viver a formação continuada a partir da experiência, e no processo de indagação encontro sentido para as teorias estudadas. Meus relatos a cada ano retratam minha experiência com a narrativa no meu fazer docente, e nesse ano não será diferente. Talvez a diferença esteja no que será narrado, no encontro com o inesperado que me leva a repensar, questionar e reinventar a minha sala de aula, o meu fazer docente. Até a próxima carta... Um abraço!

\section{CARTA II - COMO ALARGAR E VIVER O PRESENTE EM TEMPOS DE PANDEMIA?}

Rio Grande, 20 de outubro de 2020.

Até poucos dias atrás mirava o calendário, alegrava-me com os feriados, com o desejo de ter mais tempo em casa. Aqui estou na véspera de mais um feriado, e por horas esqueço o dia do mês, da semana, e acreditem esqueço dos feriados.

Dias outros que a cada amanhecer peço muita saúde a todos. Agradeço por compreender a beleza de estar vivo, de escutar o som dos pássaros e som das árvores com o vento sutil que embala os dias, e lentamente sopra ao pé do ouvido a lindeza de estar bem e em casa.

Aline Dorneles (Diário de pesquisa - 2020).

Nos últimos meses há um inquietamento em viabilizar um futuro, um futuro incerto e de infinitos questionamentos, angústias e dilemas. E, por isso escrevo, e faço reflexões desse presente vivido a cada dia. Como mulher, professora e pesquisadora encontro-me entre conflitos de estar em casa e de trabalhar em casa.

A pandemia do Covid-19 desacomodou a mim e demais docentes do seu lugar de ser e fazer a profissão docente. Há o desejo de criar possibilidades para o encontro e para a conversa com nossos alunos e com os colegas de profissão. É presente nos últimos dias o desejo de criar caminhos de se mostrar presente, e nem cabe aqui remeter a questão do 
ensino e aprendizagem. É a vontade de expressar e reafirmar que nós professores estamos aqui na busca de acolher o outro.

Por isso escrevo, e ao escrever encontro-me no tempo presente, e nele busco fazer o melhor, e, na medida do possível, me fazer presente! Seja ao escrever um e-mail para os alunos, somente para saber como estão. E, fico tão agradecida quando respondem, nem sempre alegres, porém com o desejo de partilharem seus pensamentos e suas angústias.

Por isso escrevo, como modo de narrar e documentar o sentimento de saudade do chegar em sala de aula, dos sorrisos e do sentimento de realizar meu trabalho docente.

Por isso escrevo, para reforçar a ética da profissão docente, do trabalho árduo, sem valorização profissional, sem salários dignos e, acreditem por anos pago parcelado, realidade triste e dura vivida por cada professor e professora do estado do RS.

Ao escrever encontro-me com minhas reflexões teóricas permeadas pelo olhar da experiência ontológica que, enquanto experiência, dá-se antes de toda atividade reflexionante. O verdadeiro motor da reflexão é a experiência do desconhecido e do estranho. "Trata-se aqui, sempre, de algo ou de alguém que se encontra à nossa frente e, como tal, dirige-se a nós e inquieta-nos, devido única e exclusivamente ao fato de ser outro que nós mesmos" (FLICKINGER, 2020, p.28) O autor aponta inquietudes que nos leva a pensar a ideia de reflexão humana como uma reação ao que nos acontece no mundo.

Por isso escrevo e ao escrever acalmo meu coração aflito em pensar e vivenciar uma tragédia social e política. Pois, entendo que nós professores e professoras somos vozes e gritos de uma sociedade silenciada, por isso não podemos nos calar! Por isso escrevo e questiono como (re)existir e (re)inventar à docência em tempos de pandemia?

\section{CARTA III - SOBRE O ESCREVER}

Domingo, 01 de novembro de 2020.

Às vezes tenho a impressão de que escrevo por simples curiosidade intensa.

É que, ao escrever, eu me dou as mais inesperadas surpresas.

É na hora de escrever que fico consciente das coisas, das quais, sendo inconsciente, eu antes não sabia.

Clarice Lispector (2010) 
Chegamos em novembro, e já contamos os dias para o final do ano de 2020. Como descrevemos o ano de 2020? Que difícil pensar o que está sendo e que doloroso será viver essa retrospectiva. O que aprendemos? O que vivemos? Que sentimentos cultivamos nesse ano de $2020 ?$

Nas últimas semanas talvez o que mais escuto e também digo é que estamos cansados de estar horas e horas do dia, da semana e do mês na frente das telas frias de um computador, sem o calor de um abraço, sem sorrisos, sem conversas com presença de olhares, chimarrão e gestos.

Por isso, encontro-me no escrever, e assim alimento meu desejo de estar presente comigo e com o Outro. Ao escrever posso viver inesperadas surpresas, nem sempre felizes, mas necessárias, pois é sobre o escrever nas palavras de Clarice Lispector que me encontro com o que antes eu não sabia.

Resgato pela a escrita um modo de trazer a conversa como experiência e assim o convite de abrir uma brecha no tempo, nesse tempo Kronos que nos controla com prazos, e-mails, WhatsApp e tantas outras tentativas de comunicação. Então, decido nessa carta pensar perguntas mobilizadoras para meu escrever, e assim abrir essa brecha nos afazeres, e permitir um tempo para mim.

Quem pensa no bem estar docente? Essa pergunta me provoca desde que recebi o convite para no dia 10 novembro de 2020 fazer uma fala sobre o tema. Então, como falar de bem estar no contexto vivido? Como narrar a história de vida e profissão de professoras e professores que dentro dos seus lares buscaram modos de se fazer presente na vida de cada estudante? As instituições de ensino estão preocupadas com o bem estar na docência? Quem se preocupa com o bem estar de um professor ou professora?

As perguntas levam-me a pensar no significado de bem estar atrelado ao emocional, o social e, principalmente, a condições de trabalho que oportunize o prazer e a felicidade de se fazer o que se faz. Remeto aqui a ideia filosófica de Espinosa sobre a potência de agir quando somos afetados. Desse modo, o afeto é uma afecção que faz variar positiva ou negativamente a potência de agir (GLEIZER, 2005, p.13). O aumento da potência de agir constitui a alegria, enquanto a variação negativa constitui a tristeza. 
O bem estar docente está direcionada a nossa potência de agir, que favorece a passagem para um estado mais potente do próprio ser, a alegria. A afetividade, primeiramente, tem uma relação com si mesmo na busca do que nos alegra; é encontrar razões que nos fazem aumentar nossa potência de agir. E o que nos alegra no viver e fazer docente?

Partilho algumas reflexões que, até o momento, possibilita-me pensar em 3 princípios formativos para almejar um bem estar docente. O primeiro princípio, acredito ser o encantamento pela profissão escolhida. Alegro-me em ser professora, de poder ser afetada pelas histórias de cada um, da participação ativa dos estudantes, com suas perguntas, seus saberes e aprendizagens. $O$ fato de encantar-me não me faz ser ingênua frente à histórica desvalorização da nossa profissão, mas é no encantamento que encontro força para seguir na luta pelo reconhecimento do nosso trabalho, e principalmente, é no encantamento que consigo criar modos de incentivar a escolha e permanência de acadêmicos nos cursos de Licenciatura.

Segundo princípio formativo que penso estar atrelado ao bem estar docente é o encontro com a experiência. Nos últimos tempos e, agora mais intensamente, diria que muitas coisas acontecem, a cada dia um novo desafio, seja de organizar uma aula online ou de pensar na produção de materiais para cada estudante receber em sua casa, ou adaptar-se as diferentes plataformas virtuais entre uma reunião ou outra, ufa poderia seguir! Mas, resumo dizendo que não temos fôlego para viver uma experiência.

A experiência quando vivida nos permite adentrar em outro tempo, como por exemplo, nesse momento de escrita da carta, aqui posso dizer que vivo uma experiência, ao me permitir desacelerar e com calma resgatar as expectativas, os desejos, as aprendizagens, as intenções e, nesse narrar, quiçá fazer de um acontecimento uma experiência.

O terceiro princípio formativo é o trabalho coletivo, os processos de formação em Rede. Como vivenciado na partilha de experiências da Rede Cirandar, um projeto de extensão que na sua $9^{\circ}$ edição se reinventa e fortalece os processos de formação horizontal do trabalho em Rede. No Cirandar os princípios do encantamento e da experiência são potencializados nas Rodas de Conversa. Nessa edição, temos uma Rede de 16 coordenadores que promovem encontros síncronos a cada mês com um coletivo de 
professores, técnicos em educação da universidade, professores da Escola e acadêmicos das Licenciaturas.

Desse modo, relembro de Paulo Freire e finalizo afirmando que o bem estar docente se faz com gente. Como documentado no muro de uma Escola no Chuí - RS. A imagem abaixo é o registro de quando tínhamos fomento e podíamos Cirandar nas Escolas. Com essa foto me despeço, animada para seguir meu estudo sobre o bem estar docente!

\section{Imagem 1 - Registro da Escola no Chuí - RS}

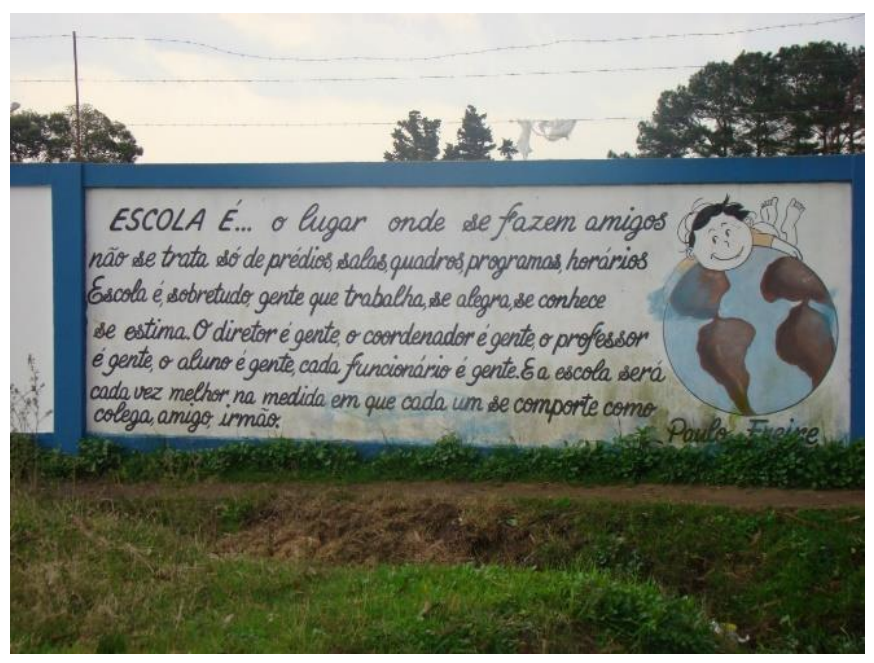

Fonte: Autora (2013).

\section{CARTA IV - É PRECISO PARAR}

Estou com saudade de mim.

Ando um pouco recolhida, atendendo demais ao telefone, escrevo depressa, vivo depressa.

Onde está eu? [...] enfim, mas que medo - de mim mesma. Clarice Lispector (2010) 
Retornei à minha segunda carta do Cirandar, fiz uma releitura, reescrevi alguns trechos e parei. Depois de 5 ou 6 dias retornei a escrita, e parei novamente. Senti a necessidade de parar, como trazido por Clarice Lispector é preciso parar! O mês de janeiro sempre teve para mim um significado especial, faço aniversário no dia 26 , e adoro comemorar o começo de um novo ciclo de vida. Lembro-me da expectativa da chegada do novo ano quando criança, os preparativos da festa de aniversário na garagem de casa, os convites rabiscados por mim em folhas coloridas, o bolo e docinhos feitos pela madrinha, e assim era possível viver a simplicidade e alegria de ser criança.

Penso que estava com saudades de mim, e nesse mês de janeiro do ano de 2021 decidi que iria viver o hoje, e assim me permitir não fazer nada, sim! Como foi difícil nos primeiros dias de férias compreender que minha casa agora poderia ser vivida sem estar horas e horas em frente a tela do celular e computador trabalhando. Então, decidi ir mais devagar, e mesmo com medo de mim mesma, encontrei-me com livros já lidos e com meu diário que a cada novo ciclo escrevo minhas reflexões e desejos. Aproveite o jardim, plantei flores, tomei banho de piscina e também fiquei deitada no sofá numa tarde chuvosa.

O que desejo levar desse encontro comigo mesma? Desejo dias menos intensos, e para isso necessito encontrar um equilíbrio entre viver e trabalhar em casa. E, para isso ter disciplina de parar e viver o agora, disciplina de encontrar o essencial a ser realizado naquele dia, sem preocupação com a lista de tarefas que ficarão anotadas na agenda, na folha de rabisco e no diário. Procuro escrever tudo que preciso fazer (faço várias anotações), e percebo que desse modo consigo desacelerar o turbilhão de pensamentos.

Permita-me dizer do prazer que tenho em escrever cartas e saber que terei na Rede do Cirandar um coletivo que acolhe, dialoga e escuta. Cada vez mais compreendo que nós professoras e professores nos fortalecemos em Rede, na partilha dos nossos escritos, reflexões, dilemas e desejos.

Retomo aqui a pergunta que mobiliza a escrita das minhas cartas e, assim um tempo de reencontro com meus escritos, leituras e estudo. Quem pensa no bem estar docente? Quero aprofundar o estudo a partir dos três princípios formativos, já apresentados na carta II, e assim almejar encontrar caminhos de constituir um bem estar docente.

O encontro com a dimensão estética no ser e estar na profissão pode nos levar ao encantamento ou, talvez, um (re)encantar-se pelo ser professor e professora. Aqui 
relaciono esse encantar-se estético com as dimensões da ética e da política na docência. Para isso, encontro-me com um pequeno livro em tamanho, mas intenso nas reflexões trazidas, intitulado a Boniteza de um Sonho escrito por Moacir Gadotti (2003). O autor diz que a esperança ainda alimenta a difícil profissão de ser docente, mesmo diante de um grande mal estar presente nas narrativas entre os docentes, com os sentimentos de impaciência, decepções, perplexidade, paradoxalmente, existe ainda muita esperança.

O encontro com dimensões formativas que alimentam a esperança aqui trazida do verso esperançar encontra-se no trabalho em Redes de formação de professores e professoras. Gadotti (2003) afirma que o sujeito que aprende através da sua experiência. Não é um coletivo que aprende. Mas é no coletivo que se aprende. No diálogo com a realidade, com autores, com meus pares, com a diferença.

Aqui remeto ao encontro com a experiência, como um princípio formativo que penso estar atrelado ao bem estar docente. Para isso, é necessário tempo, vontade, oportunidade e desejo de sistematizar suas experiências e escrever sobre elas, e ter a possibilidade de partilhar e publicizar essas experiências.

No Cirandar há esse convite para o encontro com nossas experiências, não há modelos, roteiros, e sim uma Rede de professores e professoras que no coletivo aventuram-se a viver o inesperado, às diferenças e diversidades.

A Rede Cirandar como projeto de extensão fomenta a interação de um coletivo que envolve acadêmicos das Licenciaturas, professores da educação básica, professores da universidade e demais profissionais da educação. A Rede Cirandar fortalece a escola e universidade como lugar de formação e construção de conhecimento.

Diante disso, apresento uma breve definição sobre a importância das ações extensionistas na universidade como forma de fomentar o vínculo com outros setores da sociedade da qual pertence, propiciando diálogo de saberes entre instituições existentes no entorno, bem como com os saberes populares que interagem com os saberes científicos (WALFLOR; DEVAI; VIEIRA, 2014). Assim, remeto aqui a importância de compreender as ações de extensão como modos de fomentar Redes de formação docente com intenção diálogo e partilha de saberes e experiências vividos na escola e na universidade. 
Desse modo, finalizo minha carta com o terceiro princípio formativo, sendo para mim compreendido como um princípio aglutinador, pois é no trabalho em Rede de coletivos de professores e professores que emerge o encantamento e o encontro com a experiência. É nas Rodas de Conversa permeadas de afetos, de reencontros, mesmo que online, que cada docente encontra caminhos para cultivar o bem estar.

No Cirandar nos alimentamos em nossa potência de agir, com a escrita de cartas mensais, com a escuta e leitura atenta a carta do outro, nos encontros permeados de sorrisos e transbordados de emoção que fomentamos a importância de estabelecer Redes de Conversação. Antes da pandemia a docência, muitas vezes, se fazia só, com poucas conversas trocadas nos corredores da escola, mas agora desejamos o encontro, pois sentimos falta da escola, das risadas, dos gestos, do café entre uma aula e outra, das comemorações em datas festivas, e dentre tantas coisas que nos fazem acreditar que o bem estar docente se dá na conversa e na partilha entre pares.

\section{A NARRATIVA DA EXPERIÊNCIA DOCENTE}

A experiência aqui é trazida como um modo de viver, como um caminho para compreender nosso papel como professores e professoras que afirmamos pela narrativa a importância da educação pública desse país, e mesmo diante de ataques e desvalorização docente, buscamos criar sentido e interpretações a tudo que nos acontece.

Nas cartas apresentadas busquei documentar minhas experiências como um acontecimento que me coloca a pensar, que me faz questionar e que me levam a querer investigar. As cartas são composições de sentidos a respeito da docência em tempos pandêmicos e como podemos pensar e cultivar o bem estar na docência.

Componho, a seguir meu entendimento sobre a experiência/sentido como um princípio formativo a partir da perspectiva filosófica de Jorge Larrosa $(2002,2015)$. Para o autor as palavras tem poder e determinam nosso pensamento. Assim, a palavra experiência pode ser definida como aquilo o que nos passa, o que nos acontece e o que nos toca.

O mesmo autor no seu livro Tremores: a vida, como a experiência, afirma que a relação com o mundo, com a linguagem, com os pensamentos, com os outros, com nós mesmos, com que se diz e o que se pensa, com o que somos e o que fazemos, com o que já estamos deixando de ser (LARROSA, 2015, p.74). 
A experiência aqui não é trazida como instrumento, ou uma palavra que se faz presente no dizer ou escrever. A experiência possibilita abrir caminho para o pensamento, para a linguagem, para sensibilidade e para a ação (LARROSA, 2015, p.75). É abrir-se para outro modo de pensar e fazer, e se arriscar a perguntar, dar abertura para as possibilidades do que não se sabe.

A experiência é cada vez mais rara, como afirma Benjamin (1994) no texto o narrador, no qual resgatar a importância da narrativa e do narrador, destaca que: o narrador retira da experiência o que ele conta: sua própria experiência ou a relatada pelos outros (BENJAMIN, 1994, p.201)

Jorge Larrosa também resgata as afirmações de Walter Benjamin, ao observar a pobreza de experiências que caracteriza o mundo. Em primeiro lugar pelo excesso de informação. A informação não é experiência, ela não dá lugar para a experiência (LARROSA, 2015, p. 18). Nos últimos tempos é quase uma imposição ser "bem informado", e nisso a ideia de saber muito sobre tudo, caso não se saiba, é possível a busca instantânea da informação, afinal, a mesma está em nossas mãos, na tela do celular. Nunca foi tão fácil "saber das coisas", ser um sujeito "bem informado". Tal contexto, leva-me a refletir os processos de formação de professores, como oportunizar a experiência do conhecimento, ao invés da informação? Assim, refletir a experiência do conhecimento no fazer pedagógico em sala de aula, por meio da escrita de nossas perguntas, inquietações e desejos.

Até aqui, apresentei alguns entendimentos, pensamentos e provocações a pensar os processos formativos da docência, com a proposição de que cada docente se sinta envolvido e convidado a ser autor da sua sala de aula, ser protagonista desse fazer, por vezes, silenciado e desacreditado, que o encontro com suas histórias e as histórias dos seus pares possam fortalecer esse exercício de escrita da experiência.

Vamos dar continuidade à conversa da experiência da escrita, para isso resgato a possibilidade de reencontro com o ato de narrar histórias. Walter Benjamin busca o resgate da narrativa, e nela o conceito filosófico da experiência, na década de 1930, com vestígios da Guerra Mundial em 1914. O autor destaca o declínio da experiência. No texto O narrador, reflete o papel da narrativa, resgata o momento econômico da época, com fim da atividade artesanal pela substituição do trabalho mecânico nas linhas de montagem das indústrias, e consequentemente, no plano cultural, o desaparecimento da narrativa, como uma forma "artesanal de comunicação" (FRANCO, 2015). 
Benjamin (1994) relembra a narrativa como uma forma artesanal de comunicação, pois o interesse não é transmitir o "puro em si" da coisa narrada como uma informação ou um relatório. A narrativa é um mergulho em nossas histórias de vida, nas histórias do nosso fazer docente. Como no ato de bordar, em que a artesã resgata em cada bordado o registro do seu fazer, da sua história (DORNELES, 2016).

Outro autor que estudo é Jerome Bruner, para o autor a narrativa é a forma de organizar a experiência humana. A narrativa permite viver a experiência, aqui compreendida como o modo de documentar pela escrita nossas experiências educativas. Diante disso, quero trazer algumas reflexões a respeito da narrativa, não com a preocupação de como elaborar um texto narrativo, mas de como a narrativa torna-se um importante instrumento de construção da realidade (BRUNER, 1991).

A narrativa permite assumir uma posição moral, mesmos que seja uma posição moral contra as posições morais (BRUNER, 1997). Tal afirmação fortalece nossa esperança, em tempos de desvalorização da educação e dos docentes, de desrespeito aos saberes e experiências, como também, o desconhecimento da construção de conhecimentos culturais, sociais e científicos na formação acadêmica dos profissionais da educação. Assim, a escrita narrativa torna-se artefato para documentar nosso fazer, e por meio das histórias de sala de aula firmar nossa posição moral, ética e estética enquanto docentes que lutam pela educação desse país.

Compreender a escrita da experiência pelo viés narrativo é “[ [...] explorar o que a palavra experiência nos permite pensar, o que a palavra experiência nos permite dizer, e o que a palavra experiência nos permite fazer no campo pedagógico" (LARROSA, 2015, p. 38). Reafirmo o papel formativo da narrativa, para além de um viés reflexivo da docência, mas da potencialidade de investigar o nosso fazer docente, nossas experiências educativas.

\section{ALGUMAS CONSIDERAÇÕES FINAIS}

O escrever narrativamente pode desacomodar a quem escreve e também ao leitor. No texto apresentado, inicialmente, realizei um convite para adentrar a experiência vivida, e assim refletir e questionar a respeito do que é narrado.

No projeto Cirandar a composição das cartas tem como proposição o reencontro com a autoria do próprio docente, muitas vezes perdida ou esquecida devido aos contextos educativos atrelados de burocracias e alta carga horária de trabalho. A escrita das cartas 
são a centralidade no processo de formação, oportunizando que cada docente possa tornar-se autor da sua prática educativa.

Na primeira carta a intenção foi uma apresentação a partir da pergunta como cheguei até aqui? Na segunda carta busquei indagações para fomentar o processo investigativo a partir da experiência. Na terceira e quarta carta a ideia foi narrar as ações, aprofundar o estudo e a fundamentação teórica. Cabe destacar que no processo cada docente tem autonomia para construir seu próprio diálogo com a teoria.

As cartas que compuseram esse texto tiveram como pano de fundo a docência em tempos outros, os dilemas, sentimentos e desafios vividos na pandemia. As narrativas do meu fazer docente compõem uma trama de sentidos e significados que podem ecoar e entrelaçar com outras histórias de outros professores e professoras.

O Cirandar busca pela escrita de cada docente compor essas tramas de experiências, e por isso as cartas são lidas entre pares durante o processo de formação, e cada leitor também escreve uma carta como modo de diálogo sobre o que é escrito e partilhado em cada escrita.

A narrativa da experiência docente presente na escrita de cada carta, a leitura entre pares, e a partilha da composição das cartas finais são estratégias de formação que viabilizam e convidam a cada docente sair do silêncio. A escrita da experiência torna-se um caminho de constituição de autorias do fazer educativo, de professores autores de sua prática pedagógica.

Por fim, o texto apresentado teve em cada palavra escrita um modo de retratar e documentar as experiências da docência em tempos de pandemia e assim pensar no bem estar docente. Escrevi em primeira pessoa, mas nesse dizer de mim também almejei dizer do Outro. A intenção foi partilhar as compreensões construídas desse viver e assim fortalecer um posicionamento político e ético da docência.

\section{REFERÊNCIAS}

BENJAMIN, W. O narrador, considerações sobre a obra de Nicolai Leskov. In: BENJAMIN, W. Magia e técnica, arte e política: ensaios sobre literatura e história da cultura. Obras escolhidas, v.1. 7 ed. [Trad. Sérgio Paulo Rouanet]. São Paulo: Brasiliense, 1994.

BRUNER, J. A Construção Narrativa da Realidade. Critical Inquiry, v.1, n.18, p. $1-21,1991$. 
BRUNER, J. Atos de significação. Porto Alegre: Artes Médicas, 1997.

COSTA, M. Prefácio. In: GUEDES, A.; RIBEIRO, T. Pesquisa, alteridade e experiência: metodologias minúsculas. Rio de Janeiro: Ayvu, 2019.

DORNELES, A. Rodas de Investigação Narrativa na Formação de Professores de Química: pontos bordados na partilha de experiências. Tese de doutorado. Programa de Pós-Graduação em Educação em Ciências: Química da Vida e Saúde, Universidade Federal do Rio Grande, Rio Grande, 2016.

FRANCO, B; LOLLO, J. A menina que falava bordado. Barueri, SP: Manole, 2010.

FLICKINGER, H.G. Da experiência da arte à hermenêutica filosófica. In: ALMEIDA, C.; FLICKINGER, H.G.; RONDEN, L. Hermenêutica Filosófica: nas trilhas de Hans-Georg Gadamer. Coleção Filosofia. Porto Alegre: EDIPUCRS, 2000.

GADOTTI, M. Boniteza de um sonho: ensinar-e-aprender com sentido. Novo Hamburgo: Feevale, 2003.

GUIMARÃES ROSA, J. Grande sertão: veredas. Rio de Janeiro: Nova Fronteira, 1986.

LISPECTOR, C. Crônicas para jovens: de escrita e vida. Rio de Janeiro: Rocco Jovens Leitores, 2010.

LARROSA, J. Notas sobre a experiência e o saber da experiência. Revista Brasileira de Educação, n. 19, p. 20-28, jan/abr 2002.

LARROSA, J. Tremores: escritos sobre experiência. 1 ed. Belo Horizonte: Autêntica Editora, 2015.

WALFLOR, M.; DEVAI, O.; VIEIRA, G. Interação interinstitucional: o caso do Programa de Desenvolvimento da Educação (PDE) / Universidade Federal do Paraná (UFPR) e o desenvolvimento regional. Extensão em Foco, Curitiba: Editora da UFPR, n.9, p.61-78, jan/jun 2014.

Recebido em: 29 de maio de 2021.

Aceito em: 26 de julho de 2021. 